\title{
Immediate reduction under general anesthesia and combined anterior and posterior fusion in the treatment of distraction-flexion injury in the lower cervical spine
}

\author{
De-chao Miao, Feng Wang and Yong Shen ${ }^{*}$
}

\begin{abstract}
Background: Distraction-flexion of the lower cervical spine is a severe traumatic lesion, frequently resulting in paralysis. The optimal surgical treatment is controversial. It has been a challenge for orthopedic surgeons to manage distraction-flexion injury in the lower cervical spine while avoiding the risk of iatrogenic damage. Thus, safer strategies need to be designed and adopted.This study aimed to evaluate the clinical efficacy of immediate reduction under general anesthesia and combined anterior and posterior fusion in the treatment of distractionflexion injury in the lower cervical spine.

Methods: Twenty-four subjects of traumatic lower cervical spinal distraction-flexion were retrospectively analyzed from January 2010 to December 2013. Traffic accident was the primary cause of injury, with patients presenting with dislocated segments in C4-5 $(n=8)$, C5-6 $(n=10)$, and C6-7 $(n=6)$. Sixteen patients had unilateral facet dislocation and eight had bilateral facet dislocation. Spinal injuries were classified according to the American Spinal Injury Association (ASIA) impairment scale (2000 edition amended), with four cases of grade A, four cases of grade $B$, ten cases of grade $C$, four cases of grade $D$, and two cases of grade $E$. On admission, all patients underwent immediate reduction under general anesthesia and combined anterior and posterior fusion. The mean follow-up time was 3.5 years.

Results: All operations were completed successfully, with no major complications. Postoperative X-rays showed satisfactory height for the cervical intervertebral space and recovery of the vertebral sequence. Bone fusion was completed within 4 to 6 months after surgery. Surgery also significantly improved neurological function in all patients.

Conclusion: Immediate reduction under general anesthesia and combined anterior and posterior fusion can be used to successfully treat distraction-flexion injury in the lower cervical spine, obtaining completed decompression, safe spinal re-alignment, and excellent immediate postoperative stability.
\end{abstract}

Keywords: Lower cervical spine, Spinal cord injury, Distraction-flexion, Immediate reduction, Anterior cervical approach, Posterior cervical approach

\footnotetext{
* Correspondence: 18630159778@163.com

Department of Spine Surgery, The Third Hospital of Hebei Medical University, 139 Ziqiang Road, Shijiazhuang 050051, China
}

(c) The Author(s). 2018 Open Access This article is distributed under the terms of the Creative Commons Attribution 4.0 International License (http://creativecommons.org/licenses/by/4.0/), which permits unrestricted use, distribution, and reproduction in any medium, provided you give appropriate credit to the original author(s) and the source, provide a link to the Creative Commons license, and indicate if changes were made. The Creative Commons Public Domain Dedication waiver (http://creativecommons.org/publicdomain/zero/1.0/) applies to the data made available in this article, unless otherwise stated. 


\section{Background}

Lower cervical injury is the most common type of all injuries to the cervical spine, with lower cervical facet dislocation accounting for 6 to $15 \%$ [1]. This type of injury mainly involves excessive flexion-distraction or flexion-rotation, present as the subluxation or dislocation of the facet joints and may be accompanied by spinal cord injuries [2]. Distraction-flexion of the lower cervical spine is most commonly caused by road traffic accidents and most frequently affects the levels C5-6 and C6-7 [3]. The injuries can result in significant impact on neurological function, high economic cost, and may at times be life-threatening.

The goal of treatment is to restore the normal architecture of the cervical spine, recover the anatomical and functional integrity of the spinal cord and nerve root, completely decompress and restore the intervertebral height and physiological curvature, and avoid delayed or secondary neurological injury for immediate and long-term stability of the cervical spine [4-7]. Methods described to treat distraction-flexion patients include closed traction, Halo thoracic brace, anterior or posterior approach, or both $[3,8]$. However, to date, the treatment has not been standardized. The aim of the current study was to examine the clinical efficacy of immediate reduction under general anesthesia and combined anterior and posterior fusion in the treatment of distraction-flexion injury in the lower cervical spine to provide evidence for clinical strategies.

\section{Methods}

\section{Patients}

We retrospectively reviewed our experience using immediate reduction under general anesthesia followed by antero-posterior fixation in the treatment of distraction-flexion injury in the lower cervical spine during a consecutive 4-year period (from January 2010 to December 2013). The inclusion criteria consisted of unilateral or bilateral facet dislocations, with disc herniation existed both anteriorly and posteriorly, or unstable 3-column injuries of lower cervical spine. We enrolled a final cohort of 24 patients (14 males, 10 females), who were diagnosed with distraction-flexion injury in the lower cervical spine. Patients' age ranged from 21 to 68 years, with a mean age of 44.42 years. The etiology of trauma included traffic accidents (18 patients), high falls ( 2 patients), and others ( 2 patients). All patients were imaged using cervical X-rays, CT scanning, and MRI of the cervical spine. Plain radiography and CT showed facet dislocations at C4-5 (8 patients), C56 (10 patients), and C6-7 (6 patients). Sixteen cases presented with unilateral facet dislocation and eight cases with bilateral facet dislocation. Two patients presented with intact neurological function, 4 patients with complete spinal cord injury, and 18 patients with incomplete spinal cord injury. As per the classifications of the American Spinal
Injury Association (ASIA) impairment scale [9], encompassing complete injury (grade A) to normal (grade E), we found that four cases were grade $A$, four cases were grade $B$, ten cases were grade $C$, four cases were grade $D$, and two cases were grade $\mathrm{E}$ (Table 1). Patients with clinical evidence of spinal cord injury accepted a methylprednisolone sodium succinate according to the National Acute Spinal Cord Injury StudyII protocol [2]. All patients were operated within $72 \mathrm{~h}$ following the injury. All surgeries ranged from 4 to $7 \mathrm{~h}$ in duration.

\section{Surgical technique}

A neck collar was applied to patients in the supine position. Following general anesthesia, the neck collar was removed and patients were moved into a position of mild cervical flexion. Spinal cord evoked potential monitoring was introduced to monitor the patient's neurological function during reduction. Intraoperative X-ray fluoroscopy was used to observe the reduction process. Skull traction was performed with $5 \mathrm{~kg}$ weights, and the weight was increased at a rate of $1 \mathrm{~kg}$ per $10 \mathrm{~min}$. During each interval, patients' limb neurological function changes were closely monitored and the reset situation was observed through intraoperative X-ray fluoroscopy. When the upper and lower articular process was pulled to the apex of the tip to the tip, the unilateral facet dislocation was unlocked by slight stretching of the head, allowing the inferior articular process of the dislocated vertebra to cross the superior process of the lower vertebra. Slight rotation of the neck toward the dislocated side allowed the bilateral facet dislocation to be reset. The traction weight was then gradually reduced to $5 \mathrm{~kg}$ after reduction. Traction was stopped in cases where the traction weight exceeded $15 \mathrm{~kg}$, the dislocation was unable to be reset, or neurological deterioration was observed through spinal cord evoked potential monitoring.

A standard Smith-Robinson anterior approach [10] was used to perform anterior decompression and fixation after closed traction. Plate with screw fixation and inter-body cages were used for fusion. For patients who failed closed reduction, a Caspar distractor was used to distract the intervertebral space after discectomy followed by a thin distractor for poking to achieve reduction. Then, the patient was turned to the prone position, the dislocated spinous process was fastened by lateral mass or pedicle screws and rods, fusion consisted of excising the articular cartilage and filling the articular gap with autogenous or allograft bone. Posterior decompression was also done if necessary.

A neck collar was used for 1 to 1.5 months postoperatively. All patients were graded before and after surgery according to the Japanese Orthopedic Association (JOA) score and ASIA grades to evaluate the neurological state, and the cervical curvature index (CCI) (Fig. 1) was 
Table 1 General data of enrolled cases

\begin{tabular}{|c|c|c|c|c|c|c|c|c|}
\hline $\begin{array}{l}\text { Case } \\
\text { no. }\end{array}$ & $\begin{array}{l}\text { Age } \\
\text { (year) }\end{array}$ & $\begin{array}{l}\text { Sex (male/ } \\
\text { female) }\end{array}$ & $\begin{array}{l}\text { Involved } \\
\text { segment }\end{array}$ & $\begin{array}{l}\text { Unilateral/ } \\
\text { bilateral }\end{array}$ & Spinal cord injury & $\begin{array}{l}\text { Time to } \\
\text { surgery (h) }\end{array}$ & $\begin{array}{l}\text { Traction weight } \\
(\mathrm{kg})\end{array}$ & $\begin{array}{l}\text { Time of reduction } \\
(\mathrm{min})\end{array}$ \\
\hline 1 & 33 & $M$ & C6-7 & $U$ & $\begin{array}{l}\text { Incomplete spinal cord } \\
\text { injury }\end{array}$ & 12 & 11 & 60 \\
\hline 2 & 49 & $\mathrm{~F}$ & $C 4-5$ & U & $\begin{array}{l}\text { Incomplete spinal cord } \\
\text { injury }\end{array}$ & 14 & 10 & 50 \\
\hline 3 & 68 & M & C6-7 & B & $\begin{array}{l}\text { Complete spinal cord } \\
\text { injury }\end{array}$ & 72 & 12 & 70 \\
\hline 4 & 21 & $\mathrm{~F}$ & $C 4-5$ & U & $\begin{array}{l}\text { Intact neurological } \\
\text { function }\end{array}$ & 8 & 9 & 40 \\
\hline 5 & 45 & M & C4-5 & B & $\begin{array}{l}\text { Incomplete spinal cord } \\
\text { injury }\end{array}$ & 52 & 10 & 50 \\
\hline 6 & 58 & $\mathrm{~F}$ & C5-6 & U & $\begin{array}{l}\text { Incomplete spinal cord } \\
\text { injury }\end{array}$ & 32 & 10 & 50 \\
\hline 7 & 54 & M & C5-6 & B & $\begin{array}{l}\text { Complete spinal cord } \\
\text { injury }\end{array}$ & 26 & 11 & 60 \\
\hline 8 & 46 & $\mathrm{~F}$ & C4-5 & U & $\begin{array}{l}\text { Incomplete spinal cord } \\
\text { injury }\end{array}$ & 39 & 9 & 40 \\
\hline 9 & 37 & M & C6-7 & $u$ & $\begin{array}{l}\text { Incomplete spinal cord } \\
\text { injury }\end{array}$ & 40 & 12 & 70 \\
\hline 10 & 38 & F & $C 4-5$ & B & $\begin{array}{l}\text { Incomplete spinal cord } \\
\text { injury }\end{array}$ & 44 & 9 & 40 \\
\hline 11 & 50 & M & $C 5-6$ & U & $\begin{array}{l}\text { Incomplete spinal cord } \\
\text { injury }\end{array}$ & 30 & 11 & 60 \\
\hline 12 & 34 & $\mathrm{~F}$ & $C 4-5$ & U & $\begin{array}{l}\text { Incomplete spinal cord } \\
\text { injury }\end{array}$ & 32 & 10 & 50 \\
\hline 13 & 29 & M & C5-6 & U & $\begin{array}{l}\text { Incomplete spinal cord } \\
\text { injury }\end{array}$ & 16 & 12 & 70 \\
\hline 14 & 50 & M & C6-7 & B & $\begin{array}{l}\text { Complete spinal cord } \\
\text { injury }\end{array}$ & 48 & 11 & 60 \\
\hline 15 & 42 & M & C5-6 & U & $\begin{array}{l}\text { Incomplete spinal cord } \\
\text { injury }\end{array}$ & 36 & 9 & 40 \\
\hline 16 & 39 & $\mathrm{~F}$ & $C 4-5$ & U & $\begin{array}{l}\text { Incomplete spinal cord } \\
\text { injury }\end{array}$ & 23 & 10 & 50 \\
\hline 17 & 56 & $\mathrm{~F}$ & C5-6 & B & $\begin{array}{l}\text { Complete spinal cord } \\
\text { injury }\end{array}$ & 30 & 9 & 40 \\
\hline 18 & 28 & M & C5-6 & U & $\begin{array}{l}\text { Intact neurological } \\
\text { function }\end{array}$ & 24 & 11 & 60 \\
\hline 19 & 44 & M & C4-5 & U & $\begin{array}{l}\text { Incomplete spinal cord } \\
\text { injury }\end{array}$ & 34 & 10 & 70 \\
\hline 20 & 64 & F & C5-6 & B & $\begin{array}{l}\text { Incomplete spinal cord } \\
\text { injury }\end{array}$ & 64 & 12 & 70 \\
\hline 21 & 55 & M & C6-7 & U & $\begin{array}{l}\text { Incomplete spinal cord } \\
\text { injury }\end{array}$ & 48 & 11 & 60 \\
\hline 22 & 42 & M & C5-6 & U & $\begin{array}{l}\text { Incomplete spinal cord } \\
\text { injury }\end{array}$ & 28 & 12 & 70 \\
\hline 23 & 48 & $\mathrm{~F}$ & C5-6 & B & $\begin{array}{l}\text { Incomplete spinal cord } \\
\text { injury }\end{array}$ & 28 & 11 & 60 \\
\hline 24 & 36 & M & C6-7 & U & $\begin{array}{l}\text { Incomplete spinal cord } \\
\text { injury }\end{array}$ & 40 & 11 & 60 \\
\hline Average & 44.42 & & & & & 34.17 & 10.54 & 56.25 \\
\hline
\end{tabular}


measured pre-and postoperatively to evaluate the stability of the cervical spine.

\section{Statistical method}

SPSS 22.0 statistical software (IBM, Armonk, NY, USA) was used for statistical analysis. Data was recorded as mean \pm SD and was compared by using a $t$ test. Wilcoxon rank test was applied to analyze ASIA grades that recorded preoperatively and at the latest follow-up visit. $P$ value $<0.05$ was considered statistically significant.

\section{Results}

The skull traction weight ranged from 9 to $12 \mathrm{~kg}$, with a mean of $10.54 \mathrm{~kg}$. Reduction was achieved after 40 to $70 \mathrm{~min}$ of traction (mean, $56.25 \mathrm{~min}$ ). All subjects got reduction except two patients who got reduction incompletely.

The surgery length was $328.33 \pm 47.88 \mathrm{~min}$, and the amount of blood loss was $734.58 \pm 96.68 \mathrm{ml}$. All patients were followed up for 3 to 6 years. Bone fusion was

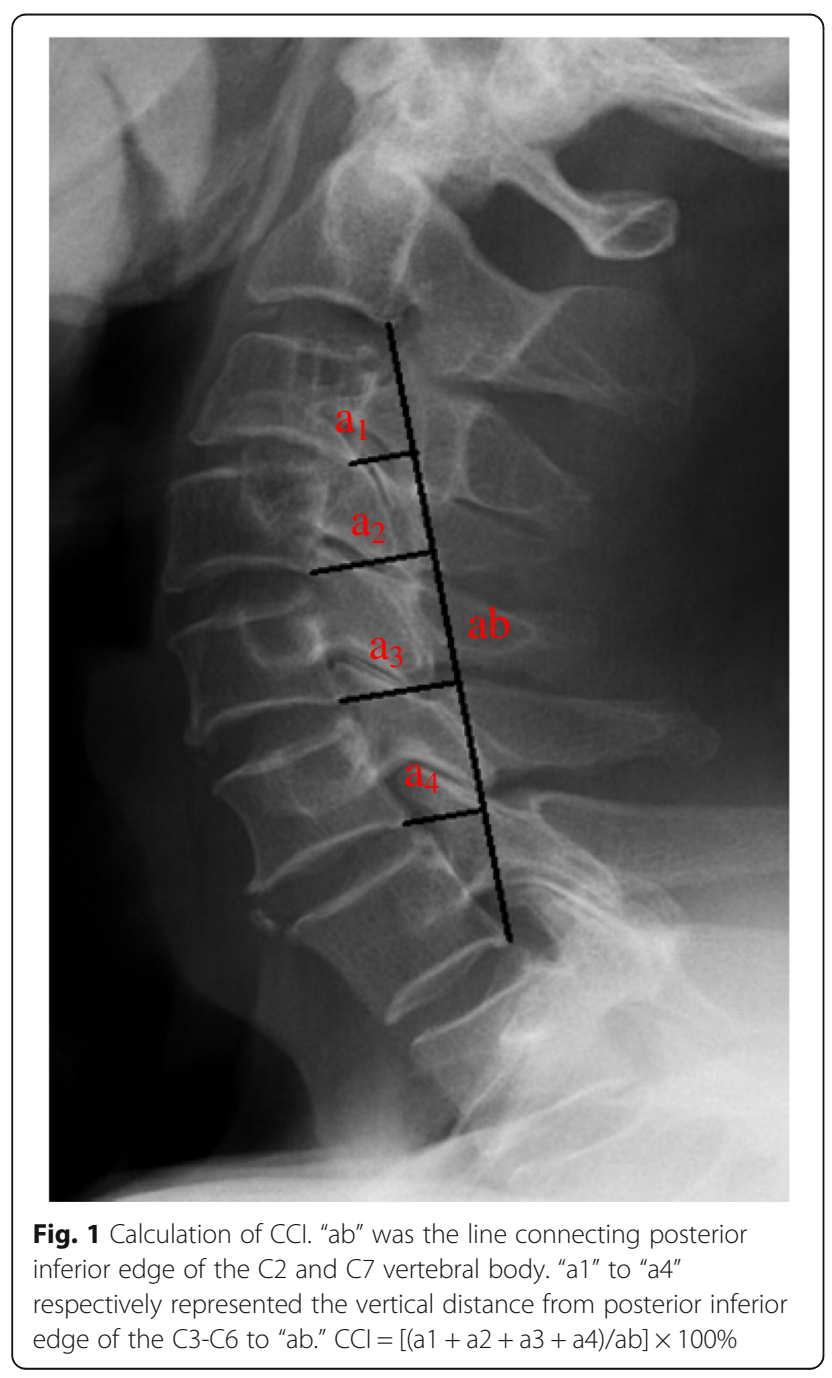

completed within 4 to 6 months after surgery (obvious fiber through and bone connections can be seen in the $\mathrm{X}$-ray and CT scans).

No severe complications were noted for any of the patients. None of the patients showed plate fracture, screw loosening, cage prolapse, or pseudarthrosis at the follow-up. X-ray examination showed satisfactory recovery of the cervical intervertebral height space and vertebral sequence.

Neurological function was also significantly improved at the follow-up as compared with preoperative values (Table 2). The paralysis plane for patients with complete spinal cord injury did not increase after surgery. Neurological function in patients with incomplete spinal cord injury was restored to varying degrees. The postoperative JOA scores and CCI showed improvement as compared with preoperative (Table 3, Fig. 2).

Although some patients complained of slight neck stiffness and discomfort postoperatively, none of them complained of neckache, limited neck activity, and a sore back. Figure 3 shows typical case imaging data.

\section{Discussion}

Distraction-flexion injuries of the lower cervical spine are usually accompanied by a disruption to the anterior or posterior elements, such as the longitudinal ligaments, the ligamentum flavum, apophyseal joint ligaments, the annulus fibrosus, and the interspinous ligaments [11], which could cause instability of the lower cervical spine. The goals of treatment of the lower cervical spine injury include a return to the normal architecture of the cervical spine, a minimum of residual pain, a recover of the functional integrity of the spinal cord, and the prevention of delayed or secondary disability [12]. However, to date, the treatment has not been standardized, and there remain several unanswered questions with regard to treatment [13]. We performed an immediate reduction under general anesthesia and followed by a combined anterior and posterior fusion and fixation in 24 patients with distraction-flexion injuries of the lower cervical spine. Bone fusion and postoperative re-alignment were obtained in all patients and maintained throughout the follow-up period.

Table 2 Pre- and postoperative ASIA grade

\begin{tabular}{|c|c|c|c|c|c|c|}
\hline \multirow{2}{*}{$\begin{array}{l}\text { ASIA } \\
\text { grade }\end{array}$} & \multirow{2}{*}{$\begin{array}{l}\text { Pre- } \\
\text { op } \\
\text { cases }\end{array}$} & \multicolumn{5}{|c|}{ The last follow-up ASIA grade } \\
\hline & & $\bar{A}$ & $B$ & C & $\mathrm{D}$ & $E$ \\
\hline A & 4 & 1 & 2 & 1 & & \\
\hline B & 4 & & 1 & 1 & 2 & \\
\hline C & 10 & & & 2 & 4 & 4 \\
\hline D & 4 & & & & 1 & 3 \\
\hline$E$ & 2 & & & & & 2 \\
\hline
\end{tabular}


Table 3 Pre- and postoperative JOA grade and cervical curvature index (CCI) and ASIA grade

\begin{tabular}{lllll}
\hline & Preoperative & The last follow-up & $p$ & Improvement rate of JOA grade (\%) \\
\hline JOA grade & $9.21 \pm 4.38$ & $13.17 \pm 4.01$ & 0.000 & $54.88 \pm 33.72$ \\
CCI & $18.90 \pm 0.91$ & $10.60 \pm 0.43$ & 0.000 & \\
ASIA grade & & 0.010 & \\
\hline
\end{tabular}

Manually closed reduction is usually initially adopted, which is a basis on which the next steps are based [13]. On the other hand, it is comprehensively accepted that cervical spine dislocations should be reduced as early as possible by closed means, because this has great impact on neurologic recovery [14]. The most common form of initial reduction has been always an attempt at awake closed reduction with skull tongs. However, awake closed reduction has some drawbacks, such as requires heavy traction weights, exposes the patients to unbearable immobilization and pain, or may cause secondary neurological injury [15-17]. However, some biomechanical studies have demonstrated the safety of skull traction [18-20]. In our study, we performed immediate reduction under general anesthesia with spinal cord evoked potential monitoring, which ensured the safety of the closed traction procedure. During the process of traction, when the upper and lower articular process was pulled to the apex of the tip to the tip, the unilateral facet dislocation was unlocked by slight stretching of the head, allowing the inferior articular process of the dislocated vertebra to cross the superior process of the lower vertebra while slight rotation of the neck toward the dislocated side allowed the bilateral facet dislocation to be reset. In this method, all subjects got reduction (two patients got reduction incompletely) and making it possible to manage the combined anterior and posterior fusion and fixation after traction.

Open reduction can be achieved through an anterior approach alone, a posterior approach alone, or a combined anterior and posterior approach [21]: the surgical approach is not standardized. Previously, anterior reduction alone was commonly used for facet dislocation patients, because anterior approach rarely causes iatrogenic soft tissue injury as it reaches the injury more directly. In addition, decompression can be achieved with direct observation of anterior pathology including rupture of the anterior longitudinal ligament or herniation or rupture of the nucleus pulposus [22]. Maynard et al. reported a series of direct anterior open reduction
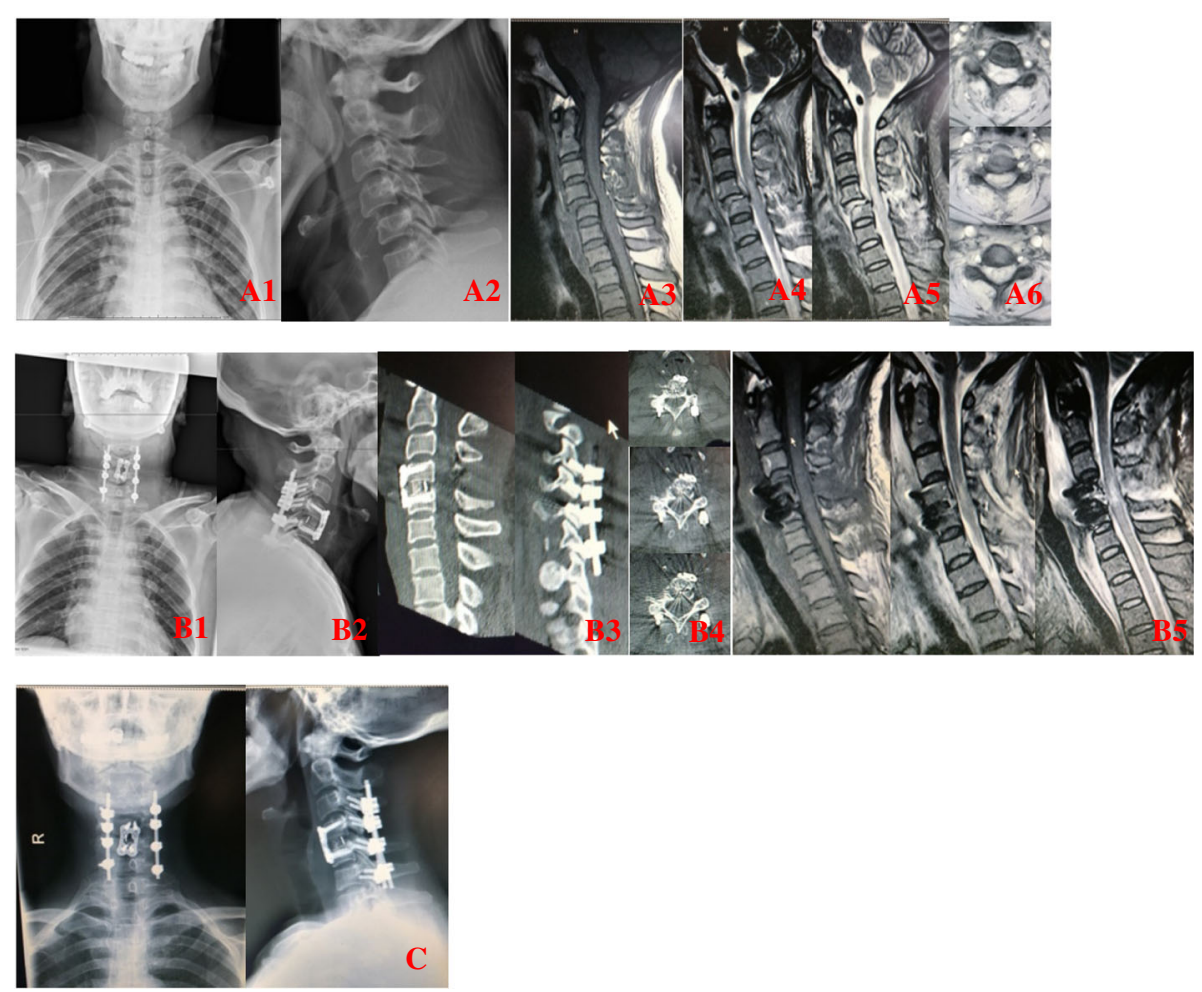

Fig. 2 Pre- and postoperative JOA grade and cervical curvature index (CCI) and ASIA grade 


\section{Pre-and postoperative JOA grade and Cervical} Curvature Index $(\mathrm{CCI})$ and ASIA grade

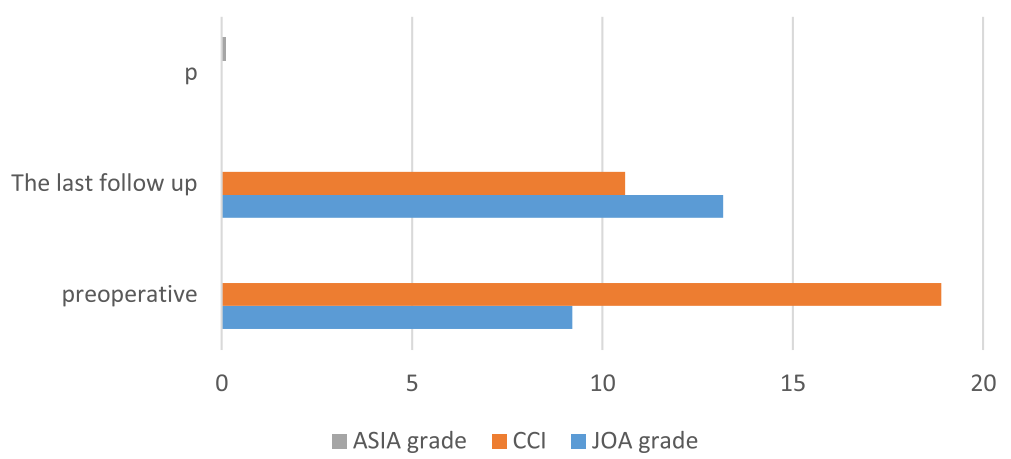

Fig. 3 A typical case imaging data. A1-A6, lateral view of radiographs demonstrated bilateral facet dislocation of C4-C5. MRI images showing disC herniation existed both anteriorly and posteriorly. B1-5, stabilization was performed via an anterior-posterior cervical approach with discectomy and fusion with inter-body cage, allograft, and Synthes plate; CT and MRI show good alignment and satisfactory decompression. C, last follow-up $X$-ray shows good alignment and union of allograft with the adjacent vertebral bodies

of distraction-flexion injuries without attempting closed reduction [23]; their procedure is very similar to the one used in our study. The increased use of an anterior approach has meant that its indication is no longer limited to injuries of anterior structures, with posterior injuries also treatable. However, Henriques et al. reported that anterior fixation alone has a lower fusion rate; 7/13 patients achieve inadequate fusion for bilateral dislocation [24]. However, many other scholars also suggest that anterior fixation alone is less effective in bilateral dislocations or cervical spine injuries with severe instability than combined approach [22, 24-26]. And a potential problem after anterior approach alone is postoperative kyphosis. Concern about the mechanical failure of distraction-flexion injuries should be high; hence, a combined anterior and posterior fusion and fixation was recommended for patients with distraction-flexion injuries, especially for patients with fractures of both facets and endplate.

Posterior open reduction can be obtained by distracting the two dislocated spinous processes with two bone-holding forceps and, if necessary, simultaneously poking the facets with a narrow osteotome. When satisfactory reduction was achieved, the cervical spine was moved into slight extension, and the dislocated spinous process fastened by lateral mass or pedicle screws. This method is a good alternative for treating distraction-flexion injuries; additionally, patients with posterior fracture or compression associated with facet dislocation, such as a lamina fragment into the canal, can be successfully treated by using a posterior approach [27]. However, posterior approach alone may add some risk of neurological deterioration in patients with anterior compression and less likely to restore cervical lordosis. Therefore, one-stage operation in combination with an anterior and posterior fusion and fixation was adopted in our study, and all patients showed evidence of stability and neurological recovery on the final follow-up examination, which is consistent with the conclusions of many studies [28-30].

The combined approach can provide the strongest internal fixation and significantly limiting motion [27]. A combined anterior and posterior fixation of the lower cervical dislocation increase the bone fusion rate, and it is helpful to restore cervical alignment and neural decompression, especially for patients with chronic injuries associated with pseudoarthrosis. A combined approach is also recommended to patients with poor bone quality, such as those with ankylosing spondylitis, osteoporosis, or other chronic conditions. However, benefits of a combined approach must be weighed against the risk of an addition surgery and increasing morbidity related to each approach as well as increasing surgical costs [29].

The timing of the surgery is another controversial aspect of this treatment. Cervical facet dislocation should be reduced as soon as possible, as recommended in the guidelines published in 2013 [31]. However, there are some risks associated with early reduction, such as neurological deterioration caused by a herniated disc or vertebral artery injury with posterior circulation stroke $[32,33]$. Nagata et al. indicated that early reduction of cervical spine dislocation ( $\leq 6 \mathrm{~h}$ of injury) might facilitate motor function improvement, even in patients with complete motor paralysis [34]. In contrast, Vaccaro suggested that a delay in surgery allows for better preoperative preparation and that decompression is safer after the edema has subsided [35]. Most authors accept that rapid reduction should give patients with distraction-flexion injuries the chance for neurological recovery or at least prevent progressive secondary spinal cord injury if the patient's condition allows. We recommend that surgery should be 
performed within $72 \mathrm{~h}$ of injury if the patient's condition permits, which is conducive to the recovery of neurological function.

The recovery of neurological injury was examined by comparing the difference in pre-operative ASIA grade and JOA scores of motor and sensory function in our study. No neurological worsening occurred; neurological function in patients with incomplete spinal cord injury was restored to varying degrees, yet symptoms of nerve root irritation had disappeared. Considering our result and previous report, an effective reduction decompression and internal fixation system for lower cervical distraction-flexion relieve neurological deterioration, provide immediate stabilization, enhance bony fusion, and correct the spine deformity [36]. However, the choice of surgical approach in the treatment of traumatic cervical dislocation is highly variable and may be influenced by a variety of factors. Nassr et al. conducted a retrospective survey analysis of surgical approach in treatment of lower cervical distraction-flexion and found that combined approach is recommended for the treatment of bilateral dislocation [29], which is in line with our findings.

In this study, we measured the CCI as described by Ishihara [37] (Fig. 1) to evaluate the stability of the cervical spine. The biomechanical superiority of posterior instrumentation and a high stability of cervical lateral mass or pedicle screws in cervical trauma have been reported [38]. However, Brodke et al. found no significant difference in stability between patients treated via an anterior approach [3]. On the other hand, Du et al. suggested that reconstruction of cervical lordosis and strengthening of cervical stability can reduce the incidence of axial symptoms [39]. As such, CCI is an important measure for evaluating the efficacy of the postoperative effect of patients with cervical spinal cord injury. We think that the CCI can also be used to predict the occurrence of adjacent segment disease after cervical surgery. More relevant studies are needed to prove its clinical significance.

The limitation of the current study is the small number of cases. However, we gained precious experience from the use of combined anterior and posterior fusion and fixation, which enable us to continuously improve and consummate the treatment of distraction-flexion injuries of the lower cervical spine.

\section{Conclusion}

Immediate reduction under general anesthesia and combined anterior and posterior fusion can be used to successfully treat distraction-flexion injury in the lower cervical spine. Complete decompression, good reduction, and recovery of the intervertebral height and curvature of the spine can be achieved through this method.

\section{Abbreviations}

ASIA: American Spinal Injury Association; CCl: Cervical curvature index; JOA: Japanese Orthopedic Association

\section{Availability of data and materials}

The datasets analyzed during the current study are available from the corresponding author on reasonable request.

\section{Authors' contributions}

D-cM performed the data collection, analyzed and interpreted the patient data, and wrote the manuscript. YS performed background research for the topic, conducted the whole study, and prepared the manuscript for submission. FW performed the data collection. All authors read and approved the final manuscript.

\section{Ethics approval and consent to participate}

All experimental protocols in this research were approved by The Third Hospital of Hebei Medical University Ethics Committee, and informed consent was obtained from all patients. The methods were carried out in accordance with the relevant guidelines, including any relevant details.

\section{Consent for publication}

Informed consent was obtained from all individual participants included in the study.

\section{Competing interests}

No benefits in any form have been or will be received from a commercial party related directly or indirectly to the subject of this manuscript.

\section{Publisher's Note}

Springer Nature remains neutral with regard to jurisdictional claims in published maps and institutional affiliations.

Received: 18 September 2017 Accepted: 21 May 2018

Published online: 29 May 2018

\section{References}

1. Maiman DJ, Barolat G, Larson SJ. Management of bilateral locked facets of the cervical spine. Neurosurgery. 1986;18(5):542-7.

2. Eismont FJ, Arena MJ, Green BA. Extrusion of an intervertebral disc associated with traumatic subluxation or dislocation of cervical facets. Case report. J Bone Joint Surg Am. 1991;73(10):1555-60.

3. Brodke DS, Anderson PA, Newell DW, Grady MS, Chapman JR. Comparison of anterior and posterior approaches in cervical spinal cord injuries. J Spinal Disord Tech. 2003;16(3):229-35.

4. Fehlings $M G$, Sekhon $\mathrm{LH}$, Tator $\mathrm{C}$. The role and timing of decompression in acute spinal cord injury: what do we know? What should we do? Spine (Phila Pa 1976). 2001;26(24 Suppl):S101-10.

5. Zhang Z, Liu C, Mu Z, et al. Anterior facetectomy for reduction of cervical facet dislocation. Spine (Phila Pa 1976). 2016;41(7):E403-9.

6. Del CD, Tamaoki MJ, Martins DE, Puertas EB, Belloti JC. Surgical approaches for cervical spine facet dislocations in adults. Cochrane Database Syst Rev. 2014;10:CD008129.

7. Ordonez BJ, Benzel EC, Naderi S, Weller SJ. Cervical facet dislocation: techniques for ventral reduction and stabilization. J Neurosurg. 2000;92(1 Suppl):18-23.

8. Woodworth RS, Molinari WJ, Brandenstein D, Gruhn W, Molinari RW Anterior cervical discectomy and fusion with structural allograft and plates for the treatment of unstable posterior cervical spine injuries. J Neurosurg Spine. 2009;10(2):93-101.

9. Bracken MB, Shepard MJ, Collins WF, et al. A randomized, controlled trial of methylprednisolone or naloxone in the treatment of acute spinal-cord injury. Results of the Second National Acute Spinal Cord Injury Study. N Engl J Med. 1990;322(20):1405-11.

10. Brodke DS, Zdeblick TA. Modified Smith-Robinson procedure for anterior cervical discectomy and fusion. Spine (Phila Pa 1976). 1992;17(10 Suppl): S427-30.

11. Ivancic PC, Pearson AM, Tominaga Y, Simpson AK, Yue JJ, Panjabi MM. Mechanism of cervical spinal cord injury during bilateral facet dislocation. Spine (Phila Pa 1976). 2007;32(22):2467-73. 
12. Aebi M. Surgical treatment of upper, middle and lower cervical injuries and non-unions by anterior procedures. Eur Spine J. 2010;19(Suppl 1):S33-9.

13. Jiang $X$, Yao $Y, Y u$ M, Cao $Y$, Yang $H$. Surgical treatment for subaxial cervical facet dislocations with incomplete or without neurological deficit: a prospective study of 52 cases. Med Sci Monit. 2017;23:732-40.

14. Lambiris E, Kasimatis GB, Tyllianakis M, Zouboulis P, Panagiotopoulos E. Treatment of unstable lower cervical spine injuries by anterior instrumented fusion alone. J Spinal Disord Tech. 2008;21(7):500-7.

15. Lee JY, Nassr A, Eck JC, Vaccaro AR. Controversies in the treatment of cervical spine dislocations. Spine J. 2009;9(5):418-23.

16. Payer M. Immediate open anterior reduction and antero-posterior fixation/ fusion for bilateral cervical locked facets. Acta Neurochir (Wien). 2005;147(5): 509-13. discussion 513-4

17. Hart RA. Cervical facet dislocation: when is magnetic resonance imaging indicated. Spine (Phila Pa 1976). 2002;27(1):116-7.

18. Miller LS, Cotler HB, De Lucia FA, Cotler JM, Hume EL. Biomechanical analysis of cervical distraction. Spine (Phila Pa 1976). 1987;12(9):831-7.

19. Onan OA, Heggeness MH, Hipp JA. A motion analysis of the cervical facet joint. Spine (Phila Pa 1976). 1998;23(4):430-9.

20. Vital JM, Gille $O$, Sénégas J, Pointillart $V$. Reduction technique for uni- and biarticular dislocations of the lower cervical spine. Spine (Phila Pa 1976). 1998;23(8):949-54. discussion 955

21. Hussain M, Nasir S, Murtaza G, Moeed U, Bari ME. Magnetic resonance imaging in cervical facet dislocation: a third world perspective. Asian Spine J. 2012:6(1):29-33.

22. Song KJ, Lee KB. Anterior versus combined anterior and posterior fixation/ fusion in the treatment of distraction-flexion injury in the lower cervical spine. J Clin Neurosci. 2008;15(1):36-42.

23. Maynard FM, Bracken MB, Creasey G, et al. International standards for neurological and functional classification of spinal cord injury. American Spinal Injury Association. Spinal Cord. 1997;35(5):266-74.

24. Henriques T, Olerud C, Bergman A, Jónsson H. Distractive flexion injuries of the subaxial cervical spine treated with anterior plate alone. J Spinal Disord Tech. 2004;17(1):1-7.

25. Vaccaro AR, Madigan L, Schweitzer ME, Flanders AE, Hilibrand AS, Albert TJ. Magnetic resonance imaging analysis of soft tissue disruption after flexiondistraction injuries of the subaxial cervical spine. Spine (Phila Pa 1976). 2001; 26(17):1866-72.

26. Pitzen $T$, Lane C, Goertzen D, et al. Anterior cervical plate fixation: biomechanical effectiveness as a function of posterior element injury. J Neurosurg. 2003;99(1 Suppl):84-90.

27. Lins CC, Prado DT, Joaquim AF. Surgical treatment of traumatic cervical facet dislocation: anterior, posterior or combined approaches? Arq Neuropsiquiatr. 2016;74(9):745-9.

28. Belirgen M, Dlouhy BJ, Grossbach AJ, Torner JC, Hitchon PW. Surgical options in the treatment of subaxial cervical fractures: a retrospective cohort study. Clin Neurol Neurosurg. 2013;115(8):1420-8.

29. Nassr A, Lee JY, Dvorak MF, et al. Variations in surgical treatment of cervical facet dislocations. Spine (Phila Pa 1976). 2008;33(7):E188-93.

30. Shen $Y$, Shen $H L$, Feng ML, Zhang WB. Immediate reduction under general anesthesia and single-staged anteroposterior spinal reconstruction for fracture-dislocation of lower cervical spine. J Spinal Disord Tech. 2015;28(1):E1-8.

31. Walters BC, Hadley MN, Hurlbert RJ, et al. Guidelines for the management of acute cervical spine and spinal cord injuries: 2013 update. Neurosurgery. 2013;60(Suppl 1):82-91.

32. Mahale YJ, Silver JR, Henderson NJ. Neurological complications of the reduction of cervical spine dislocations. J Bone Joint Surg Br. 1993; 75(3):403-9.

33. Lebl DR, Bono CM, Velmahos G, Metkar U, Nguyen J, Harris MB. Vertebral artery injury associated with blunt cervical spine trauma: a multivariate regression analysis. Spine (Phila Pa 1976). 2013;38(16):1352-61.

34. Nagata K, Inokuchi K, Chikuda H, et al. Early versus delayed reduction of cervical spine dislocation with complete motor paralysis: a multicenter study. Eur Spine J. 2017;26(4):1272-6.

35. Vaccaro AR, Daugherty RJ, Sheehan TP, et al. Neurologic outcome of early versus late surgery for cervical spinal cord injury. Spine (Phila Pa 1976). 1997; 22(22):2609-13.

36. Vaccaro AR, Cook CM, McCullen G, Garfin SR. Cervical trauma: rationale for selecting the appropriate fusion technique. Orthop Clin North Am. 1998; 29(4):745-54.
37. Takeshita K, Murakami M, Kobayashi A, Nakamura C. Relationship between cervical curvature index (Ishihara) and cervical spine angle (C2-7). J Orthop Sci. 2001;6(3):223-6.

38. Abumi $\mathrm{K}$, Ito M, Sudo $\mathrm{H}$. Reconstruction of the subaxial cervical spine using pedicle screw instrumentation. Spine (Phila Pa 1976). 2012;37(5):E349-56.

39. Du W, Wang $L$, Shen $Y$, Zhang $Y$, Ding W, Ren L. Long-term impacts of different posterior operations on curvature, neurological recovery and axial symptoms for multilevel cervical degenerative myelopathy. Eur Spine J. 2013:22(7):1594-602

\section{Ready to submit your research? Choose BMC and benefit from:}

- fast, convenient online submission

- thorough peer review by experienced researchers in your field

- rapid publication on acceptance

- support for research data, including large and complex data types

- gold Open Access which fosters wider collaboration and increased citations

- maximum visibility for your research: over $100 \mathrm{M}$ website views per year

At BMC, research is always in progress.

Learn more biomedcentral.com/submissions 